\title{
Reconocimiento y ejecución de sentencias extranjeras en materia familiar *
}

Carmen Julia Cabello Matamala

\section{Importancia del tema}

El reconocimiento y ejecución de sentencias extranjeras es un tema de interesante discusión jurídica, que ha merecido un tratamiento distinto en el tiempo y en las principales legislaciones rectoras del Derecho Internacional Privado.

En el caso peruano, la legislación civil y procesal civil han sufrido notables cambios en esta materia, particularmente en lo relativo al estado y capacidad de los nacionales.

Así, podemos observar que en cuanto a las normas sobre jurisdicción, el derogado Código de Procedimientos Civiles, en su artículo $1158^{\circ}$, establecía que «No tienen fuerza en la República las resoluciones dictadas por un tribunal extranjero, que estatuyen sobre la condición civil, capacidad personal o relaciones de familia de peruanos o de extranjeros domiciliados en el Perú».

En el caso de los nacionales, la competencia de los tribunales peruanos era exclusiva, por cuanto el factor de conexión nacionalidad excluía cualquier posibilidad de conocimiento por parte de otro Estado de asuntos de esta materia, mientras que en el caso de los extranjeros la exclusividad sólo operaba en tanto domiciliaran las partes en el país.

* Ponencia de la autora presentada en el Pleno Jurisdiccional de Familia 1999, realizado en la ciudad de Lima los días 29, 30 y 31 de enero del 2000. 
Como puede advertirse, la posición nacional era bastante restrictiva para la admisión de los exequatur, los que en su mayoría eran declarados de plano improcedentes.

El Código Civil de 1984 derogó esta norma, disponiendo respecto de la competencia internacional directa, esto es cuando los jueces nacionales conocen de los juicios originados por el ejercicio de acciones relativas al estado, capacidad y relaciones familiares; los siguientes criterios:

- Por razón del territorio: el artículo $2057^{\circ}$ contiene la norma general de competencia, señalando que los tribunales peruanos son competentes para conocer de las acciones contra personas domiciliadas en el territorio nacional.

- Por razón de la materia: el artículo $2062^{\circ}$ instituye dos casos de competencia facultativa, disponiendo a modo de excepción, que nuestros tribunales son competentes en estos juicios, aún contra personas domiciliadas en el extranjero, cuando:

- El derecho peruano es el aplicable de acuerdo a sus normas de Derecho Internacional Privado, para regir el asunto.

En lo relativo a este supuesto, debe comentarse que se ha invertido el método tradicional, al sujetarse la determinación de la competencia del juez al hecho de que sea su ley la aplicable, cuando lo usual es establecer primero el tribunal competente y luego la ley que se ha de aplicar.

- Prórroga convencional y tácita de la competencia territorial, la que opera con la condición de que la causa tenga una efectiva vinculación con el territorio de la República, observándose que el criterio de la territorialidad se subordina al de la materia. Vinculación requerida y que se materializa por hechos como la nacionalidad de alguno de los cónyuges, ser el lugar de celebración o registro del matrimonio, nacimiento o domicilio de los hijos habidos de la relación, encontrarse los bienes de la sociedad conyugal ubicados en el territorio de la República, etc. Como puede apreciarse, la labor de los magistrados en la valoración del elemento vinculante con el territorio de la República y no sólo con la legislación nacional resulta fundamental, por cuanto de no apreciarse tal vinculación, el órgano jurisdiccional debe sustraerse del conocimiento de la causa, al encontrarse frente a un caso de competencia negativa. 
Como vemos, se consagra de modo general el criterio del domicilio como factor de conexión, abandonándose el de nacionalidad para los peruanos, innovación que ha aliviado los graves inconvenientes que generaba para los nacionales tener que litigar necesariamente en el país, no obstante domiciliar en el extranjero y contar en muchos casos con derechos válidamente declarados o instituídos en procesos judiciales extranjeros; al establecerse la competencia facultativa en esta materia, los interesados pueden solicitar la homologación de los mismos ante los tribunales nacionales.

Es a través del proceso de reconocimiento y ejecución de sentencias extranjeras tradicionalmente denominado exequatur, que se inviste a la sentencia extranjera, tal como ha sido dictada, de los mismos efectos que tienen las sentencias de los jueces nacionales, sin necesidad de entrar a la revisión del juicio. Es pues, en principio, una revisión de formalidades procesales universalmente consagradas, que garantizan la observancia del debido proceso, reservándose el orden local un poder de control o de revisión de excepción, antes de prestarle la fuerza para su cumplimiento, ejerciendo nuestra judicatura una competencia internacional indirecta.

Sentís Melendo expresa «lo que se examina, no es, pues, el litigio, sino la sentencia; mejor dicho la materia litigiosa en el juicio de reconocimiento es la propia sentencia." ${ }^{1}$

El Código Procesal Civil señala con relación al reconocimiento de resoluciones judiciales y laudos expedidos en el extranjero, que el proceso al que se refiere el Título IV del Libro X del Código Civil, se interpone ante la Sala Civil de turno de la Corte Superior en cuya competencia territorial tiene su domicilio la persona contra quien se pretende hacer valer (Art. 837\%). Se establece así el criterio de competencia en razón del territorio, turno y materia, dispositivo cuya aplicación aislada podría restringir el derecho de quienes domiciliando en el país pretenden homologar una sentencia extranjera en la que el otro cónyuge domicilia en el extranjero, por cuya razón, además de esta norma, debe contemplarse la aplicación de los criterios generales de competencia del Código Procesal Civil, que comprende la prórroga convencional o tácita, posibilitándose el accionar en supuestos como el descrito.

1 Santiago Sentís Melendo, La sentencia extranjera, Buenos Aires, Ediciones Jurídicas Europa-América, 1958, p.132. 
Asimismo, el Art. $838^{\circ}$ del citado cuerpo de leyes estatuye un importante principio consagrado por la doctrina jurisprudencial nacional, la presunción relativa respecto a la existencia de la reciprocidad, norma que favorece el sistema de homologación imperante.

Como puede advertirse los cambios jurídicos son notables, la regla de declarar improcedente las solicitudes de exequatur de los nacionales, ha sido sustituída, y los casos relativos al estado y capacidad de éstos no son de competencia peruana exclusiva, sino facultativa y por tanto es posible la homologación de fallos en esta materia.

¿Qué efecto real han producido estos cambios legislativos en la carga del Despacho Superior de Familia en el Distrito Judicial de Lima?

Los datos que ha continuación se presentan han sido levantados de la Mesa de Partes de la Sala de Familia de la Corte Superior de Lima, de los libros Toma Razón correspondientes a los años 1993, 1994, 1995, 1996, 1997, 1998 y 1999.

En el caso del año 1998, se trabajó además con una muestra aleatoria de expedientes; de las 169 causas que sobre exequatur se ventilaron en la Sala se examinaron y ficharon 146 expedientes, lo que constituye una muestra de $86 \%$, información que nos permitirá aproximarnos a una lectura y reflexión de la realidad de esta institución.

\section{Cuadro 1: Incidencia de Exequatur en Derecho de Familia (unidades por Mil)}

Sala especializada de familia de la Corte Superior de lima. Periodo: 1993 - 1999

\begin{tabular}{c|c|cc|}
\hline Años & Carga Procesal & Exequatur & $\%$ \\
\hline 1993 & 4489 & 13 & 2,90 \\
\hline 1994 & 5194 & 60 & 11,55 \\
\hline 1995 & 3520 & 86 & 24,43 \\
\hline 1996 & 3756 & 63 & 16,77 \\
\hline 1997 & 3525 & 157 & 44,54 \\
\hline 1998 & 4477 & 169 & 37,75 \\
\hline 1999 & 3678 & 177 & 48,12 \\
\hline
\end{tabular}




\section{Gráfica 1: Incidencia de Exequatur en Derecho de Familia (porcentajes) \\ Período: 1993 - 1999}

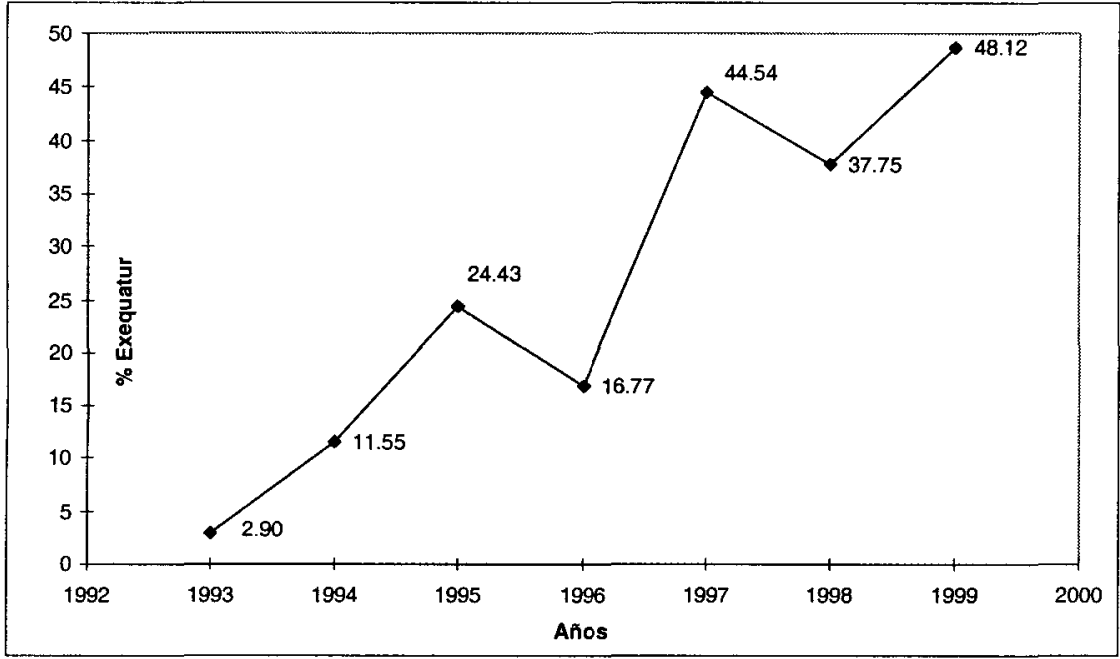

Fuente : Sala de Familia - Corte Superior de Justicia de Lima Elaboración: Carmen Julia Cabello Matamala

Cuadro 2: Distribución porcentual de Exequatur de divorcio según lugar de procedencia de la sentencia extranjera

Período: 1998

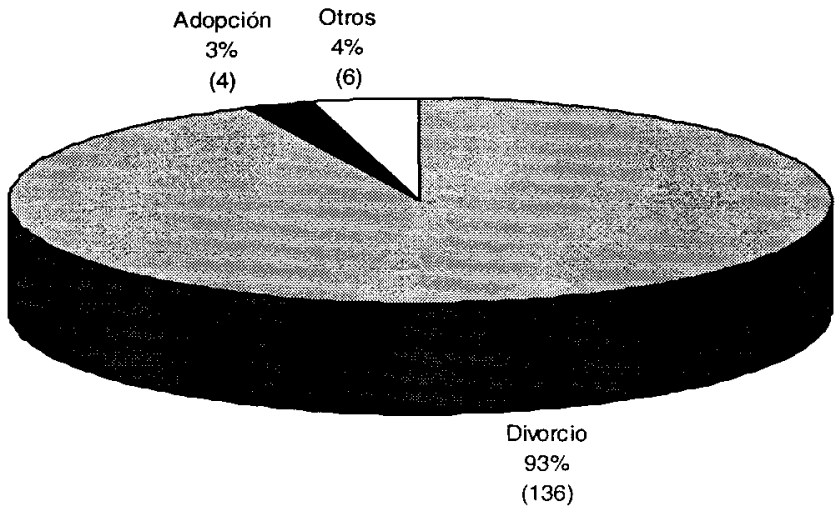

Fuente : Sala de Familia - Corte Superior de Justicia de Lima Elaboración: Carmen Julia Cabello Matamala 
Gráfica 2: Distribución porcentual de Exequatur según materia en una muestra de 146 casos.

Período: 1998.

\begin{tabular}{l|c|c} 
Pais & Casos & Porcentaje \\
\hline Estados Unidos & 79 & 58,09 \\
\hline Alemania & 14 & 10,29 \\
\hline Suiza & 14 & 10,29 \\
\hline República Dominicana & 5 & 3,68 \\
\hline España & 5 & 3,68 \\
\hline Japón & 3 & 2,21 \\
\hline Venezuela & 3 & 2,21 \\
\hline Canadá & 3 & 2,21 \\
\hline Argentina & 1 & 0,74 \\
\hline Otros & 9 & 6,62 \\
\hline Total & 136 \\
\hline
\end{tabular}

Fuente : Sala de Familia - Corte Superior de Justicia de Lima

Elaboración: Carmen Julia Cabello Matamala

Cuadro 3: Distribución porcentual de Exequatur según pronunciamiento judicial peruano.

Período: 1998.

\begin{tabular}{|l|c|c|}
\hline Pronunciamiento & Casos & Porcentaje \\
\hline Fundado & 65 & 47,79 \\
\hline Infundado & 1 & 0,74 \\
\hline Inadmisible & 61 & 44,85 \\
\hline Improcedente & 5 & 3,68 \\
\hline Desestimiento & 4 & 2,94 \\
\hline Total & 136 & 100,00 \\
\hline
\end{tabular}

Fuente : Sala de Familia - Corte Superior de Justicia de Lima

Elaboración: Carmen Julia Cabello Matamala 
Las cifras presentadas nos permiten apreciar los efectos de la significativa apertura legislativa que se ha dado para la homologación de sentencias extranjeras en asuntos familiares, especialmente en el divorcio, que constituye el porcentaje casi total de las causas. Cambios legislativos que han tenido un impacto en la realidad, particularmente los introducidos por el Código Procesal Civil al establecer la presunción relativa a favor de la existencia de la reciprocidad, cuya probanza era cuasi imposible, razón por la cual a nivel jurisprudencial se fue generando una corriente interpretativa aunque no uniforme a su favor, modificatoria que creemos ha conducido a un incremento progresivo de su incidencia en el Distrito Judicial de Lima.

Es evidente que la tasa de casos como estos irá in crecendo, pues razones de orden socio-económico han favorecido que en las últimas dos décadas el movimiento migratorio se haya intensificado no sólo dentro de nuestro país, sino que también ha operado en la traslación de nacionales al extranjero en búsqueda de nuevas oportunidades.

Nos encontramos pues, frente a una realidad concreta con cifras crecientes, tal vez numéricamente no determinantes, pero que sí ameritan definiciones jurídicas importantes por la sencilla razón de que el juez nacional viene reconociendo la eficacia de divorcios que antes denegaba de plano, a lo cual, como operador de justicia peruano con un sentido territorialista en su quehacer habitual, deberá asumir posiciones concretas frente a tendencias jurídicas en esta materia, en donde el impacto social de sus fallos, posibilitará la medición de ¿'hasta dónde el juez peruano admitirá estos divorcios?; cuestión que genera en más de uno, preocupaciones por la posible o eventual afectación del orden público o de intentos de generar fraude a la ley nacional, temas que serán motivo de desarrollo a propósito de los problemas que se van a proponer en esta unidad temática.

Habiendo delineado algunos aspectos de relevancia jurídica y de realidad en este tema, corresponde profundizar respecto al objeto materia del juicio de reconocimiento, esto es la sentencia extranjera.

\section{La sentencia extranjera y sus efectos}

Como lo señalan Ruchelli y Ferrer: «La sentencia, como producto natural del poder de soberanía, que se manifiesta mediante la jurisdic- 
ción, queda limitada, en cuanto a su eficacia, dentro de la soberanía que se ejerce.

Sin embargo, para poder comprender la validez y eficacia de la sentencia extranjera fuera de la jurisdicción que la ha creado; en otras palabras, para analizar la extraterritorialidad de la sentencia extranjera, debemos tomar posición en cuanto al análisis de la misma, teniendo presente las distintas eficacias jurídicas de la sentencia extranjera». ${ }^{2}$

¿A qué eficacias jurídicas nos estamos refiriendo? Los efectos definitivos de una sentencia firme son: fuerza de cosa juzgada, fuerza probatoria y fuerza ejecutoria.

\subsection{Fuerza de cosa juzgada}

La sentencia adquiere la autoridad de cosa juzgada cuando no es posible interponer recurso impugnatorio alguno contra ella; significa así, la eficacia definitiva y obligatoria de la declaración de derecho contenida en dicha sentencia.

Al ser la sentencia el resultado de la resolución de la controversia, queda firme cuando no se ha impugnado dicha resolución o cuando habiéndolo hecho se confirma la resolución apelada, teniendo entonces el carácter de cosa juzgada, esto significa que no se puede iniciar un proceso entre las mismas partes y con el mismo objeto ya que eso fue discutido y no existe incertidumbre jurídica que amerite un nuevo proceso; de darse este caso se puede interponer la excepción de cosa juzgada.

La excepción de cosa juzgada para Rigaux es «un medio de defensa que deriva de la fuerza obligatoria de una decisión, permite a la parte que la utiliza obstaculizar la iniciación de una nueva acción entre las mismas partes con el mismo objeto y la misma causa. Esta excepción no puede, sin embargo, invocarse respecto de algunas decisiones cuya fuerza está conectada a la persistencia de las circunstancias de hecho en que han sido dadas: así, una decisión que establece una pensión alimenticia o decide sobre la guarda de un niño es susceptible de ser revisada si la situación de las partes se modifica... ${ }^{3}$

2 Humberto Ruchelli y Horacio Ferrer, La sentencia extranjera, Buenos Aires, AbeledoPerrot, 1983, p. 10.

3 Francois Rigaux, Derecho Internacional Privado parte general, Madrid, Edit. Civitas S.A., 1985 , p. 1988 
La invocación de la cosa juzgada como excepción, de acuerdo a las normas de Derecho Internacional Privado nacional, puede hacerse valer en la vía de excepción si cumple con los requisitos establecidos para el exequatur; sin necesidad de someterla previamente a este trámite.

\subsection{Fuerza probatoria}

La Dra. Delia Revoredo, señala que el artículo $2109^{\circ}$ del Código Civil «se refiere al valor probatorio de las sentencias extranjeras legalizadas regularmente en el país de procedencia. Para efectos puramente probatorios, no requieren del procedimiento de exequatur.

Otro asunto es cuando la sentencia extranjera se intenta ejecutar en el territorio peruano, reconociéndole los mismos efectos que tienen las sentencias nacionales que gozan de autoridad de cosa juzgada. Para estos efectos no basta la legalización, sino que es necesaria la homologación de la resolución judicial conforme a las demás normas del título IV». ${ }^{4}$

Como lo refiere Mortara citado por Sentís Melendo, «la presentación de una sentencia extranjera como prueba no significa que el magistrado nacional deje de tener el poder de decidir la controversia según la propia convicción, pues la sentencia no es, en tal caso, instrumento de ejecución, sino elemento de convicción. ${ }^{5}$

Por tanto la fuerza probatoria de la sentencia extranjera es la de un documento probatorio de un hecho realizado, que si bien ha sido obtenido en otro país y bajo otras leyes, eso no es obstáculo para que pueda tener la calidad de prueba documental y será ameritada por el juez que ve la causa en el conjunto del caudal probatorio. Esta es la opción legislativa asumida por nuestro Código, concediéndole en este aspecto similar valor que a las sentencias nacionales cuando éstas se presentan como prueba ante una autoridad peruana.

\subsection{Fuerza ejecutoria}

La ejecución de las sentencias extranjeras se llevará a cabo de acuerdo a los requisitos y formalidades que establezca la legislación interna de

4 Delia Revoredo, "Exposición de motivos y comentarios" del libro Derecho Internacional Privado, Lima, p. 1036

5 Santiago Sentís Melendo, op.cit., pág.95 
cada país. Es importante recordar que no hay ejecución sin reconocimiento. Para que la sentencia tenga fuerza ejecutoria, que es el efecto extraordinario que puede tener la sentencia extranjera en nuestro país, es necesario el proceso de exequatur, porque primero debe existir un reconocimiento del órgano jurisdiccional nacional en cuanto a la sentencia expedida por tribunal extranjero; este reconocimiento no significa la revisión del fondo como ya se dijo, sino de la forma, ya que debe examinarse el cumplimiento del artículo $2104^{\circ}$ del Código Civil.

III Diferencia entre reconocimiento y ejecución de sentencias extranjeras

Weinberg señala que; «en el reconocimiento, el juez acepta un derecho consagrado por la sentencia, como, por ejemplo, la existencia de un divorcio; en la ejecución, el titular del derecho consagrado por la sentencia extranjera exige el concurso de la fuerza pública local por intermedio del juez para obtener la satisfacción material, como por ejemplo, la ejecución de bienes promovida por un acreedor». ${ }^{6}$

La diferencia entre ambos términos surge precisamente del carácter de las sentencias o decisiones, de aquellos que no necesitan ejecución por ser declarativas o constitutivas.

Un sector de la doctrina considera innecesario el procedimiento de exequatur, en el caso de las sentencias declarativas y constitutivas porque el reconocimiento debería operar ipso jure, mientras que otros sostienen que se requiere del exequatur si existe oposición de los particulares o funcionarios para la ejecución de la sentencia en mención.

IV Sistemas de reconocimiento de sentencias extranjeras

4.1 Reconocimiento restrictivo de fallos extranjeros, este es el caso de países europeos y asiáticos.

En este sistema, existe un reconocimiento de los fallos extranjeros pero bajo ciertas condiciones; por ejemplo, en Bulgaria, Holanda y la India

6 Inés Weinberg de Roca, Competencia internacional y ejecución de sentencias extranjeras, Buenos Aires, Edit. Astrea, 1994, p. 55. 
sólo procede el exequatur cuando existe tratado. En Canadá, es la Corte quien determina al final del proceso si la sentencia del país extranjero está de acuerdo o viola la ley canadiense; en el caso del Japón diremos que sí existe reconocimiento mediante el cumplimiento de ciertos requisitos, considerándose además una evaluación de manera casuística y subjetiva, esto último debido a la concepción de moral pública y buenas costumbres en dicho país.

\subsection{Reconocimiento de fallos extranjeros en países más liberales, como los Estados Unidos de América y países latinoamericanos}

El sector predominante de la legislación considera necesaria para la extraterritorialización de las ejecutorias la existencia de reciprocidad. Este sistema contiene otra limitación referida a la posible ofensa al orden público internacional de cada país donde se intente, con lo que se reduce el ámbito de ejecutividad de la sentencia extranjera. Esta limitación de orden público, no corresponde solamente al sistema de la reciprocidad, sino que constituye una limitación de carácter general y de aplicación a todos los sistemas. Al representar el sistema de la reciprocidad un dispositivo de seguridad, no de la aplicación del derecho extranjero sino de la aplicación del propio en forma extraterritorial, muchos países de concepciones amplias en materia de Derecho Internacional Privado prefieren adoptar este sistema que, en definitiva, aparece como el más apto desde el punto de vista práctico para asegurar el resultado de las sentencias dictadas en los propios territorios, de tal manera que no resulte burlado el derecho subjetivo declarado en el proceso. En este sistema, al no existir tratados entre los países, es a través de la reciprocidad existente entre los mismos que se puede reconocer y ejecutar fallos; por ello, en nuestro país la reciprocidad se presume y sólo quien la niegue deberá probarlo.

No se reconocen las sentencias dictadas en otro país, como es el caso de países árabes y musulmanes. En estos países no se reconoce a la sentencia extranjera y como consecuencia, la decisión existente en ella no será reconocida y tampoco podrá ser ejecutada. 


\section{Cuadro comparativo de la legislación internacional sobre la materia}

\begin{tabular}{|c|c|c|}
\hline & PAIS & REQUISITOS \\
\hline $\begin{array}{lll}\text { PAISES } & \text { MÁS } & \text { LIBE- } \\
\text { RALES } & & \end{array}$ & $\begin{array}{l}\text { Alemania, } \\
\text { Países latinoamericanos, } \\
\text { Austria, } \\
\text { Bélgica, } \\
\text { Brasil, } \\
\text { Corea, } \\
\text { China, } \\
\text { España, } \\
\text { Estados Unidos de América, } \\
\text { Francia, } \\
\text { Grecia, } \\
\text { Israel, } \\
\text { Italia, } \\
\text { México, } \\
\text { Nicaragua, } \\
\text { Panamá, } \\
\text { Polonia. }\end{array}$ & $\begin{array}{l}\text { Requisitos convencionales } \\
\text { Requisitos convencionales } \\
\text { Requisitos convencionales } \\
\text { requiere exequatur } \\
\text { requiere exequatur } \\
\text { Requisitos convencionales } \\
\text { Requisitos convencionales } \\
\text { Requisitos convencionales } \\
\text { Requisitos convencionales } \\
\text { Requisitos convencionales }\end{array}$ \\
\hline $\begin{array}{l}\text { PAIISES } \\
\text { MEDLANAMENTE } \\
\text { LIBERALES }\end{array}$ & $\begin{array}{l}\text { Bulgaria } \\
\text { Canadá } \\
\text { Egipto } \\
\text { Hungria } \\
\text { Japón } \\
\text { Luxemburgo } \\
\text { Marruecos }\end{array}$ & $\begin{array}{l}\text { requiere estricta reciprocidad } \\
\text { se debe iniciar proced. Local } \\
\text { prefiere convenio bilateral } \\
\text { la acepta, pero es muy subjet } \\
\text { requiere exequatur } \\
\text { requiere exequatur }\end{array}$ \\
\hline $\begin{array}{l}\text { PAÍSES MÁS } \\
\text { TRICTIVOS }\end{array}$ & $\begin{array}{l}\text { Australia } \\
\text { Dinamarca } \\
\text { Finlandia } \\
\text { Gran Bretańa } \\
\text { Holanda } \\
\text { Indonesia } \\
\text { Malasia } \\
\text { Nueva Zelandia }\end{array}$ & $\begin{array}{l}\text { no acepta } \\
\text { no acepta, sólo der. de familia } \\
\text { no acepta, sólo países europeos } \\
\text { no acepta } \\
\text { sólo si hay convenio bilateral } \\
\text { no acepta } \\
\text { sólo si hay convenio bilateral } \\
\text { no acepta }\end{array}$ \\
\hline OTROS PAISES & Paraguay & Poder Judicial no sabe si es posible \\
\hline
\end{tabular}

*Requisitos convencionales: reciprocidad, tribunal competente, sentencia ejecutoria, notificación del demandado, fallo extranjero consistente con la ley local, etc.

Fuente: Ejecución y Reconocimiento de sentencias extranjeras, Ministerio de Relaciones Exteriores. Perú. 1995, p. 91.

\section{Sistema peruano de reconocimiento de sentencias extranjeras}

El Código Civil, por primera vez de modo sistemático, trata la materia de Derecho Internacional Privado, la cual antes se encontraba dispersa en la Constitución de 1933 y en la de 1979, en el título preliminar del Código Civil de 1936 y en el Código de Procedimientos Civiles, en leyes especiales y en decretos leyes. $\mathrm{Al}$ respecto, al clarificarse 
los casos de jurisdicción peruana exclusiva así como los de negativa, admitiéndose que para ciertos asuntos la jurisdicción peruana positiva es facultativa, se reconoce expresamente que en estos asuntos son competentes los jueces peruanos como los extranjeros, por tanto las sentencias o fallos extranjeros resultantes deben ser reconocibles en el Perú y es precisamente el Título IV sobre reconocimiento y ejecución de sentencias y fallos arbitrales extranjeros, el que establece las condiciones y formas que deben observarse para otorgar eficacia a dichos mandatos judiciales.

\section{Requisitos de procedencia}

El artículo $2104^{\circ}$ establece los requisitos de procedencia para el reconocimiento y ejecución de sentencias extranjeras, puntualizando ocho requerimientos:

1. Que no resuelvan asuntos de competencia peruana exclusiva.

2. Que el tribunal extranjero haya sido competente para conocer el asunto de acuerdo a sus normas de Derecho Internacional Privado y a los principios generales de competencia procesal internacional.

3. Que se haya citado al demandado conforme a la ley del lugar del proceso; que se le haya concedido plazo razonable para comparecer; y que se le hayan otorgado garantías procesales para defenderse.

4. Que la sentencia tenga autoridad de cosa juzgada en el concepto de las leyes del lugar del proceso.

5. Que no exista en el Perú juicio pendiente entre las mismas partes y sobre el mismo objeto, iniciado con anterioridad a la interposición de la demanda que originó la sentencia.

6. Que no sea incompatible con otra sentencia que reúna los requisitos de reconocimiento y ejecución exigidos en este título y que haya sido dictada anteriormente.

7. Que no sea contraria al orden público ni a las buenas costumbres.

8. Que se pruebe la reciprocidad.?

7 Modificado por el artículo $838^{\circ}$ del Código Procesal Civil:Se presume que existe 
Dichos requisitos se encuentran ilustrados en los fallos superiores y supremos que se han presentado en el material de lectura para información de los presentes, más; serán motivo de reflexión en este evento tres puntos centrales de diálogo:

- El primero vinculado al objeto de la solicitud de exequatur, esto es la sentencia extranjera que detente la autoridad de cosa juzgada en el concepto de las leyes del lugar del proceso; y ello a propósito de las reiteradas solicitudes de reconocimiento formuladas por connacionales que pretenden la homologación de una resolución administrativa municipal, que dispone la disolución del matrimonio celebrado en el Japón e inscrito en los registros consulares peruanos.

- El segundo relativo a la afectación o no al orden público en los casos de homologación de una sentencia extranjera que declare el divorcio por una causal no prevista en la ley nacional.

- El tercero relativo a la oportunidad desde la cual surte efectos en nuestro país la sentencia extranjera: ¿de la fecha de expedición de la sentencia de exequatur? o ¿declarada la homologación, los efectos de la sentencia extranjera se retrotraen en el Perú a la fecha de su expedición por el tribunal extranjero?

\subsection{Objeto de la solicitud de exequatur}

En relación con el primer tema relativo a la homologación de sentencias extranjeras con carácter de cosa juzgada, es necesario precisar el alcance terminológico de la expresión sentencia.

Sentencia o decisión judicial extranjera son los términos que usualmente se emplean para señalar a la materia del procedimiento de exequatur. Como bien lo define la Convención de la Haya en su artículo $2^{\circ}$; se entiende como decisión judicial a la que sea reconocida y declarada ejecutoria en el país requerido, y que a la vez no puede ser objeto de un recurso extraordinario en el país de origen. Surge entonces la necesidad de distinguir la sentencia extranjera y el auxilio judicial internacional.

reciprocidad respecto a la fuerza que se da en el extranjero a las sentencias o laudos pronunciados en el Perú. Corresponde la prueba negativa a quien niegue la reciprocidad. 
- Auxilio judicial internacional

«Las cartas rogatorias constituyen el ruego y apoderamiento que dirige un juez o tribunal de otro país para que realice determinados actos procesales. (Ej.: notificación de una decisión, interrogatorio de un testigo, etc.) $)^{8}$

Lecompte señala que «los exhortos o comisiones rogatorias son las diligencias mediante las cuales los jueces se suplican entre sí para llevar a cabo ciertas actuaciones judiciales como notificaciones, práctica de pruebas, etc; ya sea dentro del territorio del estado en el cual administran justicia o hacia los que ejercen jurisdicción en otros.»"

De lo que se colige que a pesar de que sean emitidos por un órgano con poder jurisdiccional no son materia de reconocimiento, al tratarse meramente de actos judiciales de carácter administrativo.

¿En este aspecto podrían ser objeto de exequatur las resoluciones expedidas en procesos no contenciosos, de jurisdicción voluntaria?

- Resoluciones judiciales expedidas en procesos no contenciosos

Lagarmilla dice «que en los actos de jurisdicción voluntaria no se trata de contradecir derecho alguno, ni de obligar a terceros sino que se va a la autoridad judicial a autenticar un acto unilateral, en el que no se concibe la existencia de parte demandada, tratándose de procedimientos judiciales ${ }^{10}$

Mortara señala: «la providencia de jurisdicción voluntaria no es, en realidad, un acto de función jurisdiccional soberana; por lo mismo, no puede adquirir autoridad de cosa juzgada y no puede ser ejecutada forzosamente sobre los bienes o contra la persona de quien se oponga a ello.».11

Calamandrei afirma que «la llamada jurisdicción voluntaria no es tal jurisdicción sino que es administración ejercida por órganos judiciales.» $^{12}$

8 Ministerio de Relaciones Exteriores, «Ejecución y reconocimiento de sentencias extranjeras", Gaceta Jurídica, 1995, p.11

9 Alvaro Lecompte Luna, Derecho Internacional Privado, Bogotá, Edit. Temis, 1979, p. 122

10 Santiago Sentís Melendo, op. cit., p.51

11 Santiago Sentís Melendo, op. cit., p. 56

12 Santiago Sentís Melendo, op. cit. , p.52 
De ahí que nuestra ley expresamente en el segundo párrafo del artículo $2108^{\circ}$ del Código Civil señale que las sentencias extranjeras que versen sobre asuntos no contenciosos de jurisdicción facultativa no requieren exequatur.

Explica la Dra. Revoredo que «las sentencias extranjeras sobre asuntos de jurisdicción graciosa, no requieren de exequatur, quedando sus efectos limitados a los de un medio probatorio.. ${ }^{13}$

Otra discusión que se plantea es en torno a que si el amparo judicial de la resolución sólo debe comprender a las de carácter jurisdiccional, o corresponde incluir a las resoluciones que expidan o autoricen funcionarios administrativos ajenos al ámbito jurisdiccional. Santiago Sentís señala: «Los actos jurídicos no han de contemplarse desde el punto de vista del país en que se pide el exequatur, sino del país de origen. Un acto será judicial o administrativo según lo regule la legislación del país en que se ha producido, sin que en el extranjero sea posible cambiar su naturaleza jurídica. El que un acto sea judicial o administrativo, lleva consigo no sólo un origen diferente, sino procedimiento distinto y garantías más o menos sólidas. Si los actos judiciales merecen una determinada consideración y ser objeto de tratados o legislación interna en un determinado sentido, no es lógico extender el contenido de estos tratados o preceptos a unos actos que, aún cuando por su naturaleza hubieran debido ser judiciales, sin embargo, se desarrollaron en la órbita administrativa.. ${ }^{14}$

De similar opinión Ruchelli y Ferrer afirman categóricamente que "deben excluírse en principio las resoluciones que realicen o autoricen funcionarios administrativos ajenos al ámbito jurisdiccional.» ${ }^{15}$

Existen precedentes internacionales importantes; en el caso de la Comunidad Europea, en el año 1998 se ha suscrito el Convenio sobre la competencia, el reconocimiento y la ejecución de resoluciones judiciales en materia matrimonial, el cual incluye en el ámbito del Convenio a las acciones judiciales civiles, así como a otros procedimientos no judiciales admitidos para el ámbito matrimonial en determinados Estados; se refiere entonces a procedimientos administrativos que son oficialmente reconocidos por un Estado miembro. En el caso de Di-

13 Delia Revoredo, op. cit. p. 1035

14 Santiago Sentís Melendo, op. cit. pp.38-39

15 Humberto Ruchelli y Horacio Ferrer, op. cit., p. 27 
namarca, por ejemplo, existe junto a la vía jurisdiccional, la vía administrativa y para poder acudir a ella es necesario que haya una causa de divorcio, que exista un acuerdo entre las partes no sólo sobre el divorcio sino además sobre temas vinculados a él. Las resoluciones dictadas por el órgano administrativo pueden ser recurridas ante el Ministerio de Justicia, cuya decisión se encontrará sujeta a revisión judicial en la vía ordinaria.

Por tanto, como puede establecerse a nivel de la Comunidad Europea, es admisible el reconocimiento de resoluciones judiciales como administrativas en el ámbito matrimonial y de relaciones parentales.

Cierto es que son cada vez más frecuentes, por lo menos en la Corte Superior de Lima, las solicitudes de exequatur de resoluciones administrativas que declaran el divorcio, provenientes particularmente de peruanos que han contraído matrimonio en el Japón, que lo han inscrito en los registros consulares respectivos, cuyo domicilio conyugal ha tenido como sede el Japón y que mediante acuerdo han logrado la disolución administrativa autorizada expresamente en la ley de Koseki. Al respecto, el Consulado General del Japón informó a la Dirección de Asuntos Consulares del Ministerio de Relaciones Exteriores del Perú, mediante documento de fecha 20 de enero de 1997, que de acuerdo al Código Civil de Japón los divorcios pueden ser por mutuo acuerdo (artículo $763^{\circ}$ ) o mediante proceso judicial (artículo $770^{\circ}$ ). Señala que en el primer caso si los cónyuges están de acuerdo en divorciarse, deberán tramitar el divorcio según la ley de Koseki (Ley del Registro Familiar), ante los municipios.

En el segundo caso, cuando exista sentencia de divorcio el asiento de ésta deberá tramitarse, según la referida ley, ante los municipios. En ambos casos los alcaldes de los municipios están facultados para expedir certificados de divorcios, resultando sumamente lógico para las partes que si nuestros registros admitieron la inscripción del matrimonio, admitan en consecuencia la inscripción de la disolución.

$\mathrm{Al}$ respecto, se plantean dos posiciones a debatir; de un lado, la observancia de las formalidades requeridas por las normas de Derecho Internacional Privado nacional en materia de reconocimiento y ejecución de sentencias extranjeras, que han sido en parte descritas en la explicación precedente $\mathrm{y}$, de otro lado, la razonabilidad del pedido formulado ante el órgano jurisdiccional nacional, de justiciables que invocan su derecho a una tutela jurisdiccional efectiva para el ejercicio 
de un derecho legítimamente constituido en el extranjero, a un juez nacional que no puede dejar de administrar justicia por defecto o deficiencia de la ley, que por mandato de la misma debe aplicar los principios generales del derecho, preferentemente los que inspiran el derecho peruano.

\subsection{Orden público internacional versus numerus clausus de las causales de divorcio}

Con relación al segundo tema, orden público versus numerus clausus de las causales de divorcio en la ley nacional, existen dos posiciones planteadas. La primera que sostiene que las normas relativas al matrimonio y familia como instituciones naturales y fundamentales de la sociedad, son de orden público y de cumplimiento obligatorio y, en consecuencia, en el Perú las causales para demandar el divorcio absoluto son numerus clausus no admitiéndose, por tanto, la homologación de sentencias de divorcios por causales distintas a las establecidas por la ley nacional. En contra de la posición descrita se formula la siguiente: no hay afectación al orden público internacional por cuanto la ley peruana, modificando el sistema anterior, ha admitido que los nacionales puedan ser divorciados ante un tribunal extranjero sujetándose a la ley del domicilio conyugal, modificando la jurisdicción que era de carácter exclusivo a facultativo.

El tema de orden público internacional es de difícil comprensión; intentaremos aproximarnos a él deduciéndolo de la comparación entre la justicia conflictual y diferencia de la justicia sustancial.

En las relaciones jurídicas de carácter nacional, por el principio de territorialidad, los asuntos de competencia y ley aplicable se encuentran claramente definidos en la legislación interna, cuya estructura lógica tiene los siguientes elementos: el supuesto, que es la hipótesis que de ocurrir desencadena una consecuencia; la consecuencia que es el efecto atribuído por el Derecho a la verificación del supuesto en la realidad y el nexo lógico-jurídico que es el elemento lógico vinculante.

De otro lado, en cambio, la justicia conflictual debe resolver los conflictos generados en una relación jurídica de carácter internacional aplicando a cada relación jurídica en cuestión la ley material del país que, de acuerdo a las normas de Derecho Internacional Privado, tienen competencia para regirla. Es así que la estructura de la norma de 
Derecho Internacional Privado, denominada también normas conflictuales, sea distinta a la norma material interna, presentando como elementos: la categoría genérica abstracta, que es el concepto que pretende englobar en su enunciado toda posible relación que sea comprendida en ella; y el punto de contacto o elemento de conexión, que establece cual es la ley aplicable, ya que señala qué sistema jurídico va a regular esa situación jurídica.

Se presenta así muchas veces una incomprensión de la justicia conflictual versus la justicia sustancial que ignora el problema conflictual.

Cuando la divergencia es tan grande que implica una absoluta incompatibilidad entre los criterios del derecho extranjero y los principios fundamentales de justicia de la lex fori, el juez debe excluir las disposiciones correspondientes del derecho extranjero (Artículo 2049 del Código Civil).

Es necesario distinguir la noción de orden público interno de la de orden público internacional. Al respecto, las normas del derecho peruano de carácter imperativo, que no pueden modificarse a la voluntad de los individuos, son de orden público interno; en tanto que el orden público internacional tiene que ver con la naturaleza de normas peruanas y que no pueden ser descartadas por la aplicación de leyes extranjeras.

Alfonsín afirma: «Esta distinción pone de manifiesto que si bien todo precepto de orden público internacional es a fortiori de orden público interno, la inversa no es igualmente verdadera, por lo cual no basta que una norma sea de orden publico interno para fundar en ella una excepción de orden público internacional. $\aleph^{16}$

El tema que en este punto se plantea es si las causales de divorcio previstas en la ley nacional ameritan sustentar la excepción de orden público, que excluiría la aplicación de la legislación extranjera en materia de divorcio en asuntos de conocimiento por parte del juez peruano o, como en el caso de exequatur cuando se trata de reconocer situaciones jurídicas ya creadas.

Como lo distingue Sánchez-Covisa, la cláusula de reserva o de orden público internacional debe tener un campo de aplicación más restringido cuando se trata de reconocer situaciones jurídicas válida- 
mente creadas en un sistema jurídico extranjero, que cuando se trata de crear situaciones jurídicas en el seno del sistema jurídico nacional.

Se hace necesario así discriminar la noción de orden público en el terreno de creación de los derechos y la noción de orden público en el terreno de la eficacia de los derechos. En el primer caso, se trata de crear en el propio país derechos y situaciones jurídicas mediante la aplicación directa de la ley material extranjera, en tanto que en el segundo, se trata simplemente de reconocer derechos adquiridos y situaciones jurídicas definitivamente constituídas en el extranjero. Ello ha venido a denominarse: doctrina de efecto atenuado del orden público. En el mismo artículo el autor nos refiere como la jurisprudencia francesa desde mediados de este siglo ha venido imponiendo la siguiente tesis:

La tesis fue claramente consagrada en el famoso caso Rivière sentenciado por la Corte de Casación en el año 1953. Se trataba de un divorcio por mutuo consentimiento decretado por un tribunal ecuatoriano entre una mujer francesa y un marido de origen ruso domiciliados en Ecuador. A pesar de que el divorcio por mutuo consentimiento no está consagrado en la legislación francesa y se considera - en cuanto tal- contrario al orden público internacional francés, la Casación reconoció la validez del divorcio. Arguyó que «la reacción frente a una disposición contraria al orden público no es la misma según que imponga obstáculos a la adquisición de un derecho en Francia o según que se trate de dejar producir en Francia los efectos de un derecho adquirido sin fraude, en el extranjero y de acuerdo con la ley a quien el derecho internacional privado francés otorga competencia.» «La doctrina del efecto atenuado del orden público cuando se trata de reconocer derechos válidamente creados en el extranjero puede hoy considerarse incorporada a la doctrina y a la jurisprudencia francesa. Ha recibido aplicación en una serie de campos, como, por ejemplo, para admitir el reconocimiento en el extranjero de un hijo adulterino o para admitir que una de las mujeres de un extranjero polígamo reclame alimentos en Francia a su maridom. ${ }^{17}$

17 Joaquín Sánchez-Covisa, Orden público internacional y divorcio vincular, 1970, p. 
Se admite de este modo que la sentencia dictada en el país del domicilio será reconocida en los demás países.

En los países del Common Law el control del orden público se ha concentrado en forma prácticamente exclusiva en el control de la regularidad procesal del juicio.

Por naturaleza, el exequatur es un simple reconocimiento u homologación, un simple dar fuerza ejecutoria a lo decidido por el juez extranjero, y no un nuevo juicio o una nueva valoración de los hechos por el tribunal nacional. Por ello, es necesario distinguir el ámbito de la excepción del orden público, que como tal debería ser restringido y no extensivo; supuesto distinto es la improcedencia de la homologación porque se trata de sentencias extranjeras procesalmente irregulares, porque hayan sido dictadas por un tribunal que carezca de jurisdicción o de competencia internacional o porque se hayan infringido los principios que aseguran su regularidad procesal, como son los vinculados a la citación del demandado, su razonable posibilidad de defensa que posibilite una real controversia judicial.

La posición que sustenta que no se afecta al orden público al homologar sentencias de divorcios por causales no previstas en la ley nacional, acusan como se dijo, que el divorcio ya no es una materia de competencia exclusiva del Perú, estableciendo expresamente el artículo $2082^{\circ}$ del Código Civil que las causas de separación de cuerpos y divorcio se someten a la ley del lugar del domicilio conyugal, deduciendo que la voluntad de la ley peruana es autorizar que un matrimonio celebrado en el Perú o inscrito en el Perú pueda ser disuelto aplicándose la ley extranjera, invocándose causales previstas en la ley del domicilio conyugal, por tanto, no habiéndose trasgredido principios fundamentales del ordenamiento constitucional peruano, ni evidenciándose la intención de provocar un fraude a la ley nacional, no resultaría suficiente para amparar la excepción de orden público internacional.

\subsection{Eficacia en el Perú de la sentencia extranjera}

Con relación al tercer tema vinculado a la efectividad del fallo extranjero en el país, es necesario precisar algunos alcances respecto a la naturaleza procesal de la acción de exequatur y de la sentencia de exequatur. 
En principio, respecto al carácter de la acción, se trata de una acción autónoma, la materia litigiosa a diferencia de la sentencia extranjera no lo constituye la relación jurídica sustancial sobre la cual se ha pronunciado el fallo extranjero; en el caso del exequatur, la materia litigiosa está constituída por la misma sentencia independiente de la litis que le ha dado origen.

La acción se fundamenta en el principio de soberanía nacional que establece el efecto territorial de los fallos, razón por la cual es necesario que el juez nacionalice la sentencia extranjera, convirtiéndola en un elemento jurídico nacional, luego de verificado los requisitos que la ley establece para estos efectos.

\section{¿Que carácter ostenta la sentencia de exequatur?}

Un sector de la doctrina sostiene que tiene un carácter constitutivo por cuanto sólo mediante la intervención del juez nacional se puede obtener en el país los efectos de la sentencia extranjera; de otro lado, quienes sostienen su carácter declarativo consideran respecto a la naturaleza de la sentencia de reconocimiento, que el juicio de delibación y reconocimiento no crea la sentencia sino que la declara ejecutoria, por cuanto ésta no pronuncia un mandato de contenido idéntico al de la sentencia extranjera sino un mandato aceptando la idoneidad de ésta para producir efectos en el propio Estado.

De ahí que quienes sostienen la segunda posición postulen que no se trata de efectos de la sentencia nacional de reconocimiento, sino de efectos de la sentencia extranjera, argumentando que la sentencia es una sola y sus efectos son los mismos cualquiera que sea el lugar donde haya de producirse y, en ese entendido, otorgando a la homologación los efectos de la sentencia extranjera en el país, se retrotraerían a la fecha en que fue expedido el fallo materia de reconocimiento; mientras que quienes sostienen el carácter constitutivo de la sentencia de exequatur postularían que la sentencia extranjera recién genera efectos en el territorio nacional cuando se ha expedido ésta, como requisito indispensable para el valor y eficacia de la sentencia extranjera que sólo mediante dicho procedimiento los adquiriría.

Como puede advertirse la materia de cuestionamiento e inquietud jurídica en esta temática es profusa, nos hemos permitido proponer tres temas puntuales de diálogo no obstante como podrá advertirse de 
los materiales entregados, los diez casos presentados ofrecen a su lector un caudal importante de reflexión y cuestionamiento y es que tal vez, como Ruchelli y Ferrer lo plantean en el fondo lo que existe es el enfrentamiento de "dos concepciones fundamentales en el campo del Derecho Internacional Privado, la universalista que tienden a facilitar la extraterritorialidad de la sentencia, evitando al mismo tiempo la intervención estatal que frustre o dificulte el agotamiento de la relación jurídica y la nacionalista que convierte los requisitos para el reconocimiento y ejecución de las sentencias extranjeras, en la exigencia de un acto que las incorpore al ordenamiento nacional. No se aplicaría en consecuencia ni decisión extranjera ni derecho extranjero sino el propio." ${ }^{18}$

Cierto es que los estudiosos de esta especialidad podrán converger o diverger con estos planteamientos interpretativos, más, seremos los magistrados quienes a través de nuestros fallos orientaremos su sentido y alcance, impulsando jurisprudencialmente el desarrollo de ésta importante área del derecho privado internacional. 